\title{
Livelihoods Sustainability in Agriculture-Intensive Semi-Arid and Dry Sub-Humid Areas of West Africa - Pointers from Nigeria
}

\section{Usman M. T. and AbdulKadir A.}

\author{
Department of Geography, Federal University of Technology, PMB 65, Minna, Bosso Campus \\ 920003, Niger State, Nigeria.
}

Keywords: Environmental Uncertainties, Agriculture, poverty, insecurity, and sustainable livelihood

\begin{abstract}
Agricultural intensification has been adopted as a viable option for Poverty eradication and hunger, attainment of food security, socio-economic wellbeing as well as sustainable livelihood across the West Africa sub-humid and semi-arid zones. Thus, there is need to identify and address the challenges of sustainable livelihoods in the agriculture-intensive semi-arid and dry sub-humid zones of West Africa. This was addressed through review of relevant literature and analysis of environmental parameters from recent research by the authors to unveil the environmental uncertainties that threaten the sustainability of agriculture and human livelihoods across the ecologically fragile regions of West Africa, using pointers from Nigeria. The research identified the fundamental challenges, adaptation and mitigation approaches to environmental constraints, and requirements for reducing risk, enhance agricultural resilience as well as livelihoods in the zones. This was based on the premise that primarily, the use of adequate and accurately derived environmental information is crucial for increased agricultural productivity, sustainability of economic diversification and human livelihoods and by implication, enhanced regional and national security.
\end{abstract}

Keywords: Environmental Uncertainties, Agriculture, poverty, insecurity, and sustainable livelihood 


\section{Introduction}

Vast populations in West Africa's semi-arid and sub-humid zones are engaged in seasonal rainfalldependent subsistence agriculture and have continued to intensify their agricultural practices for enhanced livelihoods without required results. The agricultural intensification has been through large scale slash and burn, adoption of improved genetic species, agro-chemicals; fertilizers and herbicides. All these focus towards Poverty eradication, attainment of security food security and socio-economic wellbeing as well as sustainable livelihood across the zones. Furthermore, the productivity from intensified agricultural activities is mostly threatened by erratic moisture quality and its distribution that characterize the entire zone couple with land degradation across the zone in response to over cultivation. Cropping practices in dry lands are directly governed by the low rainfall patterns (Giovannucci, 2012). These have been aggravating community's vulnerability thereby reducing their resilience in the wake of external shocks or deviation from normal such as drought and flood, which usually have devastating impact on crops, livestock and socio-economic livelihoods. Climate variability and change are perhaps the most serious environmental threat to the fight against hunger, malnutrition, disease and poverty in Africa, mainly through its impact on agricultural productivity (Anselm and Taofeeq 2010, Gukurume 2013 and Temesgen et.al 2014). By implication, monitoring moisture quality, pattern and distribution for the identification of the crop suitability and adaptability is crucial for the attainment of the economic diversification and sustainable livelihood.

Farmers in the region are in acute poverty because rainfall variability, evolving climate change and land degradation continues to pose great challenges for their resource-based livelihoods and they lack the capability to cope with and recover from the stresses and shocks of their fragile environment. Jamal (2015) stated that about $75 \%$ of Africa's poor (living on less than $\$ 1.25 /$ day) live in countries where people living in drylands make up more than $25 \%$ of total population. It is pertinent to note that a fundamental problem to address across the zone would remain povertyaggravating insecurity in countries like Niger, Mali, Burkina Faso, Chad and Nigeria. Since climate change is expected to further exacerbate food insecurity in such areas currently vulnerable to hunger and undernutrition (Wheeler and Von 2013). Rainfall patterns and distribution of seasonal rainfall is critical for agricultural productivity thereby a major driver of livelihood across the agricultural-intensive zones of semi arid and dry sub-humid areas of West Africa. There is large consensus that in West Africa one of the major climate change impacts will be on rainfall, making it more variable and less reliable (Beno^1t 2012). Hence, it's crucial to Identify location specific moisture challenges across the zones for understanding and identification of sustainable practices for enhance socio-economic livelihood.

Primarily, the Nigeria economy is characterized by over dependence on petroleum resource, thus fluctuation in global crude market always impact drastically on the economy resulting to decline national income. This necessitates the Government effort towards diversification of the economic since 2015 as pathway toward enhance socio-economic development, attainment of food security and sustainable livelihood. In general, most West African countries in recent times rely on food importation to feed the population mainly due climate variability and its challenges. Consequently, the attainment of sustainable economic diversification in a region where about two-third of the population depends of rain-fed agriculture for livelihood is a function of identifying and addressing erratic moisture challenges typical of these zones and incorporating the adaptation policy into economic diversification plan and implementation. A climate justice perspective will be used to 
recommend necessary actions to assist resource-poor farmers who are most affected by climate change but have contributed least to it, so that countries in the zone can enhance their food security and speed their economic growth (Bruce et.al 2014). Identification of environmental stresses is crucial for the development of adequate and accurate information for adaptation and mitigation strategies for sustainable agriculture and by implication, enhancing national and regional economic diversification, security and sustainable livelihoods.

Consequently, is pertinent to identify the challenges and prospects of sustainable livelihoods in the agriculture-intensive semi-arid and dry sub-humid zones of West Africa. This will be addressed through review of relevant literature and analysis of environmental parameters from recent research by the authors to unveil the environmental uncertainties that threaten the sustainability of agriculture and human livelihoods across the ecologically fragile regions of West Africa, using pointers from Nigeria. The focus will be to identify fundamental challenges, adaptation and mitigation approaches to environmental constraints, and requirements for enhancing agricultural resilience as well as livelihoods in the zones. It will be based on the premise that primarily, adequate and accurately derived environmental information is crucial to increased productivity, sustainability of economic diversification and human livelihoods, and by implication, enhanced regional and national security.

\section{Climatic Features of Semi-Arid and Dry Sub-Humid Areas of West Africa}

The rainfall distribution across West Africa is characterized by large-scale intra-seasonal and interannual variability. The seasonal pattern of rainfall is determined by the north-south seasonal migration of the inter-tropical convergence zone (ITCZ) following the position of maximum surface heating associated with the meridional displacement of the overhead position of the sun (Menghestab 2005). The semi-arid and dry sub-humid climatic zones dominate large proportion of West Africa land area extending between longitude $0-16^{0}$ East and West of Greenwich Meridian and latitude $9-13^{0}$ North of the Equator. Gaoussou and Erika (2015) described the subhumid zone as characterized with 180 - 270 days of rainfall, semi-arid 75-180 while the arid zone receive less than 75 days of rainfall (Fig.1). By this classification, if the rainfall is well distributed (homogeneous) across the 180-270 days then the zone has the potential to support varying types of root and cereal species as well sustained human livelihood. However, it's pertinent to identify and address the variability that intensifies moisture stress and the potential impact on intensive agricultural practice across the zones. Given the fact that water availability is a key component of agricultural productivity and by extension food security, erratic rainfall thus constrained the sustainability of agricultural activities especially in regions that naturally receives very low annual rainfall Gukurume (2013). The spatio-temporal variability in rainfall constitutes the prime factor threatening intensive agriculture in sub-humid and semi-arid zones of West Africa. 


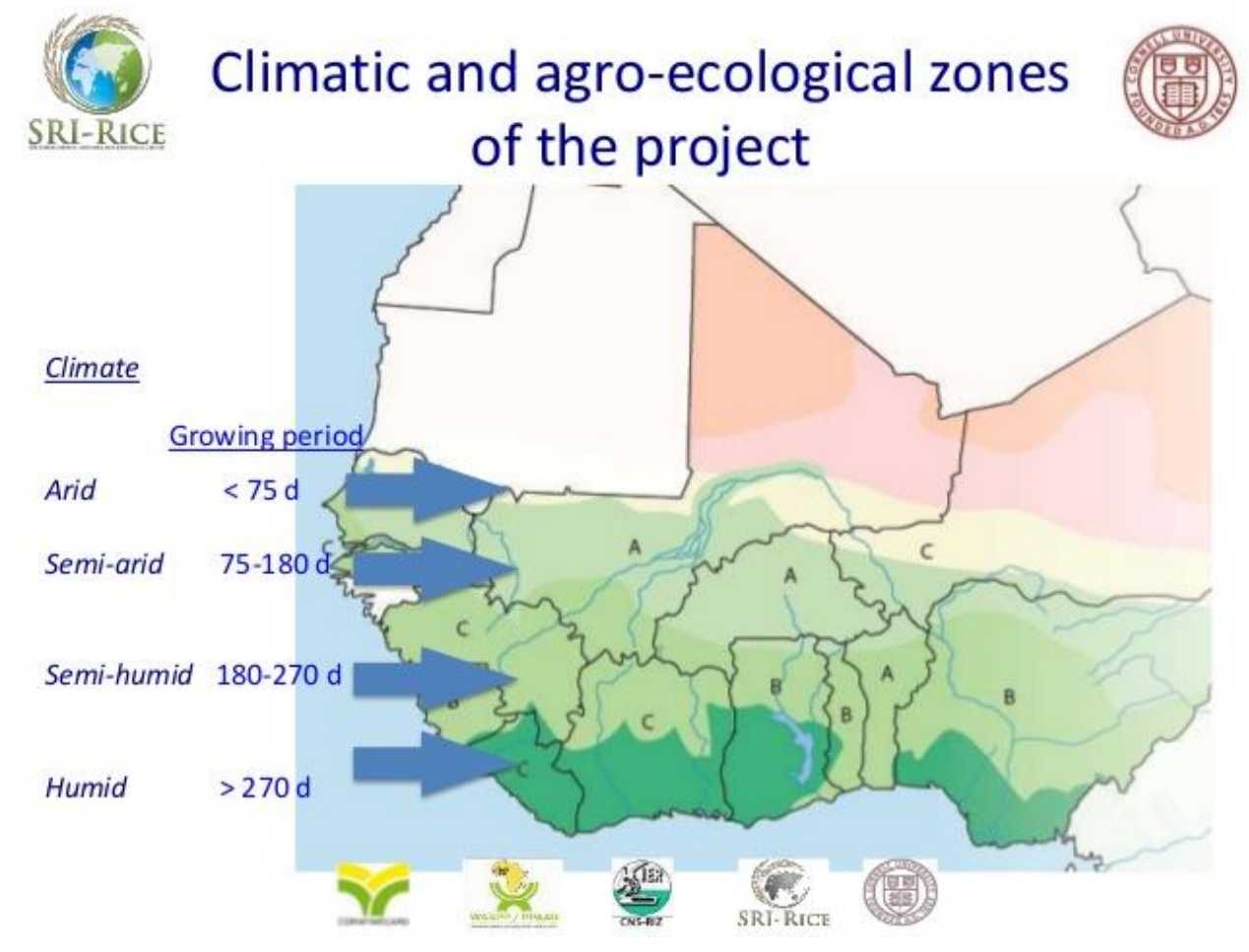

Source: Gaoussou and Erika (2015)

Generally, rainfall in these zones is erratic, insufficient, unevenly distributed during the short growing season. High variability in both rainfall amounts and intensities are characteristics of dryland regions, as are the occurrence of prolonged periods of drought (FAO 2010).These similarly impact on relevant socio-economic sector such as agriculture and in so doing determine type crops cultivated; cereals (rice, wheat, sorghum, groundnut, millet and others) that dominates regional agricultural output. Rainfall variability has inevitably threatened the sustainability of agriculture as well as the livelihood activity for many peasant farmers (Gukurume, 2013 and Mary and Chukwudi 2014). Consequently, all countries in West Africa are classified by the 2012 Global Hunger Index (GHI) as being characterized with alarming or serious hunger index except Ghana that was moderate. This is because seasonal rainfall uncertainty directly or indirectly leads crop failure and decline yield thereby reducing food availability and attainment of food security at local, state, national and regional levels. Most of the countries with alarming GHI scores are in SubSaharan Africa and South Asia (GHI 2012). The semi-arid and dry sub-humid zones of West Africa are largely area of pastoral and short wet season intensive cropping practice across the fragile marginal ecosystem. Shabbir and Abdullah (2013) affirmed that dry land itself indicates marginality due to water stress.

It is fundamental to note that the observed increasing temperatures couple with changed rainfall patterns is drastically altering the classic climatic zones. As researches have confirmed that each of the past several decades has been significantly warmer than the previous one (Taalas 2016 and Hansen et.al, 2010). By implication, these have continued to intensify aridity and changing the geographical distribution of areas suited to specific crop thus, affecting annual crop yield and 
escalating poverty. Also Gukurume (2013), concluded that shifts in seasonal precipitation being experienced have adversely affected productivity. The impact of these are apparent; recurring crop failure, aridity, poverty and famine intensifying community and regional crisis, southward migration and in extreme case inter-regional migration despite the risk. Climate variability and change are perhaps the most serious environmental threat to the fight against hunger, malnutrition, disease and poverty in Africa, mainly through its impact on agricultural productivity (Anselm and Taofeeq 2010, Gukurume 2013 and Temesgen et.al 2014). Identification of these climatic uncertainties and there consequences for agriculture and food sustainability is crucial to the attainment of sustainable intensification of agriculture, eradication of poverty, hunger and food security which will in turn minimize all forms of migration and the resultant socio-cultural, economic and political crisis.

\section{Challenges of Agriculture-Intensification in Semi-Arid and Dry Sub-Humid Zones}

High variability in both rainfall amounts and intensities are characteristics of dry land regions, as are the occurrence of prolonged periods of drought (FAO 2010). This constitutes a major threat to the attainment of agricultural intensification across West Africa, her poverty reduction efforts and sustainable livelihood strategies. Rainfall variability has inevitably threatened the sustainability of agriculture as a livelihood activity for many peasant farmers (Gukurume 2013 and Mary and Chukwudi. 2014). By implication, aggravating regional vulnerability as most countries are characterized by wide variety of seasonal rainfall induced hazards such as droughts, floods, pest infestation, erosion and land slide that could be disastrous leading to loss of livelihoods, property, and human lives. Climate variability and change has become a topical is- sue in recent time because of its largely detrimental impacts on natural and human systems (Emmanuel and Fanan 2013). Identification of these precarious moisture variability and quality are paramount to limiting the adverse impacts on the intensive agriculture and livelihoods of rural populations as well a tool to the attainment of sustainable livelihood.

Drought which signify period of less than normal/deficient moisture is the commonest environmental hazard that gradually threatens agricultural productivity across the semi-arid and dry sub-humid area of West Africa. The West African Sahel is well known for the severe droughts that ravaged the region in the 1970s and 1980s Nicholson (2013). This affects a large number of people, live stock, crop as well aggravate environmental degradation and aridity in the region. In large regions of Africa, where water is a limiting factor and people strongly rely on rain-fed agriculture, droughts have frequently led to crop failure, food shortages and even humanitarian crises (Winkler et.al 2017). The semi-arid and dry sub-humid zones of West Africa are vulnerable to varying types of drought; meteorological-deficit in rainfall amount, agricultural-shortage in crop water requirement and hydrological shortfall in surface and ground water recharge.

These generally have negative consequences on the sustainability of agricultural intensification across the zones and by implication aggravating the resultant socio-economical drought that is typical of the region. Drought alone has caused more deaths during the last century than any other physical hazard (FAO 2013). Historically, drought is a common phenomenon across the region 
that is usually characterized by spatio-temporal variation in its occurrence and intensity. Propastin et.al (2010) stated that drought events have caused more than 800,000 deaths and affected about 262 million people in Africa during 1900-2013. Hence, the need for a better understanding of this spatio-temporal patterns and characteristics of droughts affecting agriculture intensive sub-humid and dry semi arid areas of West Africa as a pathway towards the attainment of economic diversification and enhance livelihood.

Furthermore, climate change is intensifying environmental changes which in turn constitute a major challenge to attainment of economic diversification across the region where large proportion of the population depends on natural recourse base for livelihood. In Sub-Sahara Africa, agriculture plays a very important role in providing food and income for the majority of the population (Mary and Majule 2009). The sub-humid and semi-arid zones of West Africa are vulnerable to climate change because of their geographic location, low capacity, and greater reliance on climate sensitive and dependence on rainfall agriculture for socio-economic livelihood. Millions of Africa's rural dwellers wholly depend on weather patterns "nature's benevolence" for good harvest year on year (Kevin, 2014). The changes in climate have continued to intensify moisture stress and extreme weather events such as droughts, excessive rains and the resultant floods that constitute major risk factors affecting agricultural productivity, sustainable livelihood, food and socio-economic security across the region. Gukurume (2013) argues that climate change has compounded the vulnerability of peasant farmers in the drought - prone district of Bikita plunging them into food insecurity and abject poverty. As lack of rain as at when needed during the growing season directly and indirectly leads to crop failure and in extreme cases death of livestock in so doing, reducing food availability, decline income and intensify poverty. Extreme weather events touch every economic and social sector, including the foundation of civilization agriculture (Richard 2015). Consequently, the identification of these is paramount to development, planning and implementation of adaptation and mitigation strategies for the attainment of sustainable agricultural intensification and socio-economic development across the region.

Extreme weather conditions (drought and flood) are fundamental environmental problem facing most part sub-humid and semi-arid zones of West Africa. The livelihoods of 2.5 billion smallholders depend on agriculture and worldwide, over 500 million people depend, directly or indirectly, on fisheries and aquaculture (FAO 2013). This is not only affecting the general socioeconomic livelihood of inhabitant but also, the living conditions and exacerbating natural resource (land, water and vegetation) degradation thereby intensifying desertification. This coupled with population growth is exerting pressure on socio-economic wellbeing across the zone due to its fundamental impact on agriculture and attainment of food security. The situation when all people, at all times, have physical, social and economic access to sufficient, safe and nutritious food that meets their dietary needs and food preferences for an active and healthy life (FAO 2002). The recurring Crop failure, hunger, famine and force migration that is typical in recent times signals the need to identify ways and strategies for adapting and mitigating the increasingly unpredictable environment changes for the sustainability of intensive agriculture, food security and the resultant livelihood across the sub-humid and dry semi-arid zone of West Africa.

\section{Nigeria Scenario; Challenges, Adaptation and Mitigation Approaches}


The spatio-temporal variability in the occurrence of rainfall and its impact are apparent across Nigeria. In the last century, the 1970s and 1980s drought have devastating impact on humanity through loss of life, disappearance of the famous groundnut pyramid, crop failures and death of livestock which led to food shortage, famine and dependence on food importation to meet national demand till date. About 18 million people were estimated to be at risk of starvation, mainly because of poor harvests in several countries (GHI 2012). The erratic weather condition couples with the quest for food to feed the ever growing population have force the farmers in the sub-humid and semi-arid zones of Nigeria to adopt intensive agricultural system as way out of acute poverty and hunger. Greater climate variability which incorporates the later onset, higher temperatures and increased potential evapotranspiration will make farming systems more highly vulnerable to climate change (Beno 1t 2012). In response to this, more land were put under cultivation through deforestation that generally accelerates global warming, soil erosion, land degradation as well as altering the natural equilibrium that exist between the earth components. Widely accepted predictions show that the on-going pattern of climate change will not only raise temperatures across the globe, but will also intensify the water cycle, reinforcing existing patterns of water scarcity and abundance, increasing the risk of droughts and floods (FAO, 2010).

Rainfall variability has continued to pose a great treat to the sustainability of intensive agriculture across the sub-humid and semi-arid zones of Nigeria. The variability and its impact on agricultural sustainability and attainment of food security were obvious in the fluctuations of crop yields and local food supplies in Nigeria. Thus, this a prime challenge to the sustainability of intensive agriculture across the fragile ecosystem. Consequently, an Intra-seasonal Rainfall Monitoring Index (IRMI, Usman and Abdulkadir, 2012)) was developed to monitor rainfall from onset to cessation. This Index is a function of both quantity and spread $\left(C p t^{2}\right) /(h p t \times N b \times 100)$; Where $\mathrm{Cpt}$, hpt and $\mathrm{Nb}$ are Cumulative pentad rainfall since, highest pentad total rainfall, Number of breaks in rainfall since may 1 and 100 is a factor respectively. This has the potential to identify moisture quality, it effectiveness and associated seasonal potential hazard timely (Table 2). In rural areas that depend on rainfed agriculture for an important part of their local food supply, changes in the amount and timing of rainfall within the season and an increase in weather variability are likely to aggravate the precariousness of local food systems (FAO, 2008). The Scheme was developed to capture the varying levels of moisture quality and drought categories from abundant, adequate, deficient, very deficient and extremely deficient moisture conditions that transit to seasonal hazards; flood to extremely severe drought. These are fundamental tool for adaptation to erratic moisture condition typical sub-humid and semi-arid zones of West Africa also, it's crucial for the sustainability of agricultural intensification and human livelihood. 
Table 2: IRMI-based Drought Monitoring Scheme

\begin{tabular}{|l|l|l|l|}
\hline \multicolumn{2}{|l|}{ ON SET CLASSIFICATION } & $\begin{array}{l}\text { RAINFALL RECEIPT (MOISTURE } \\
\text { SUPPLY CONDITION) }\end{array}$ & $\begin{array}{l}\text { HAZARD } \\
\text { CATEGORIES }\end{array}$ \\
\hline IRMI RANGES & IRMI CLASSES & $\begin{array}{l}\text { Abundant (High rainfall total within } \\
\text { short time spans) }\end{array}$ & Flood \\
\hline IRMI $>10$ & 1 & Adequate & No drought, No flood \\
\hline $1<\mathrm{IRMI} \leq 10$ & 2 & Deficient & Mild drought \\
\hline $0.1<\mathrm{IRMI} \leq 1$ & 3 & Very deficient & $\begin{array}{l}\text { Extremely deficient (Low rainfall totals } \\
\text { over long time spans) }\end{array}$ \\
\hline $0.01<\mathrm{IRMI} \leq 0.1$ & 4 & 5 & Very severe drought \\
\hline IRMI $\leq 0.01$ & &
\end{tabular}

Source: Usman and Abdulkadir 2013

Drought poses threat to food access for Nigerian populations through decline in agricultural produce and incomes thereby increasing risk of food, socio-economic and socio-cultural insecurity across the region. Masihi et.al (2014) concludes that available evidence from the past clearly shows that the African continent is likely to face extreme and widespread droughts in future. The recurring drought have been aggravating unemployment across the country as large proportion of youthful population are unemployed and these have continued to serve as push factor for both internal and inter-regional migration as well as promoting crime, criminality and insecurity across the country. Muhammad et.al (2005) highlighted that drought is not just important for meteorological phenomena but also because of the impact upon human well being and push towards environmental degradation. The study recommended the development and adoption of operational definition for analyzing drought frequency, severity and duration for monitoring rainfall quality and its impact agriculture in sub-humid and semi-arid zones.

Consequently, Monsoon Quality Index (MQI) was developed to measures the quality of the seasonal rains in terms of both annual amounts and seasonal spread as $M Q I=\left(r_{m m i} * N b_{i}\right) / R_{i}^{2}$

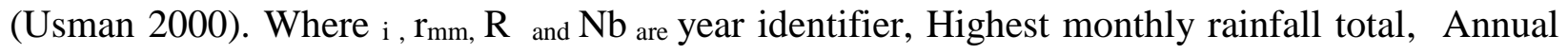
rainfall total and Number of 'breaks' in rainfall respectively. Also, a break is taken as any pentad period with less than $5 \mathrm{~mm}$ of rain. It's indicated that the index is small if the annual amount is high and the rains are not concentrated in any one month. By implication the smaller the index, the better the seasonal moisture quality agriculturally thus, it is a tool for identification of interseasonal and inter-annual moisture stress which is crucial for the development of national and regional adaptation strategies. The paper concluded that recent fluctuations in rainfall regimes over most dry sub-humid and semi arid areas and the associated threats of famine, starvation and mass wasting of human population, have underscored the need for reliable climate forecast in aid of agriculture. The MQI values were classified $(<0.005$ - >0.02) to depict the varying moisture 
conditions ranging from good to Extremely poor and interpreted as no drought to extremely severe drought (Table 1) to prompt the needful adaptation through adoption of fast maturing species and issuance of early warning scheme.

Table1: MQI Class

\begin{tabular}{|l|l|l|l|}
\hline $\begin{array}{l}\text { MQI } \\
\text { Class }\end{array}$ & MQI Value & $\begin{array}{l}\text { Rainfall } \\
\text { Performance }\end{array}$ & Drought Category \\
\hline 1 & $<0.005$ & Good & No Drought \\
\hline 2 & $\geq 0.005<0.01$ & Fair & Mild Drought \\
\hline 3 & $\geq 0.01<0.015$ & Poor & Severe Drought \\
\hline 4 & $\geq 0.015<0.02$ & Very Poor & Very Severe Drought \\
\hline 5 & $>0.02$ & Extremely Poor & Extremely Severe Drought \\
\hline
\end{tabular}

Source: Usman 2000

Application of this Scheme to Nguru, Sokoto and Zaria using 56 years (1950-2006) rainfall record unveil the varying levels of moisture stress typical of the sub-humid and semi-arid zones of Nigeria (Fig.2). Moisture quality in generally good in Zaria expects 1983 and 1999 that were characterized by mild drought. Poor moisture quality is typical of Sokoto as 2/3 of years experience mild drought, severe drought recorded in 1950, 1956, 1973, 1978, 1979, 1980, 1982, 1983, 1984, 1985, 1992, 1993, 1995, 1997, 1998 and 2000 while 1969, 1970, 1972 and 1981 illustrate very severe drought and 1957,1968 and 1994 indicates the occurrence of extremely severe drought. Pertinent to note is the fact that Nguru is characterized by very poor and extremely poor moisture condition which is typical of most semi-arid zones; this unveils the recurring server, very severe and extremely severe drought across the north east. Hence, it is essential to identify and develop specific adaptation strategies for this precarious moisture condition that have been hindering the sustainability of agriculture productivity and socio-economic livelihood which sequentially have continued to aggravate insecurity across the northeast.

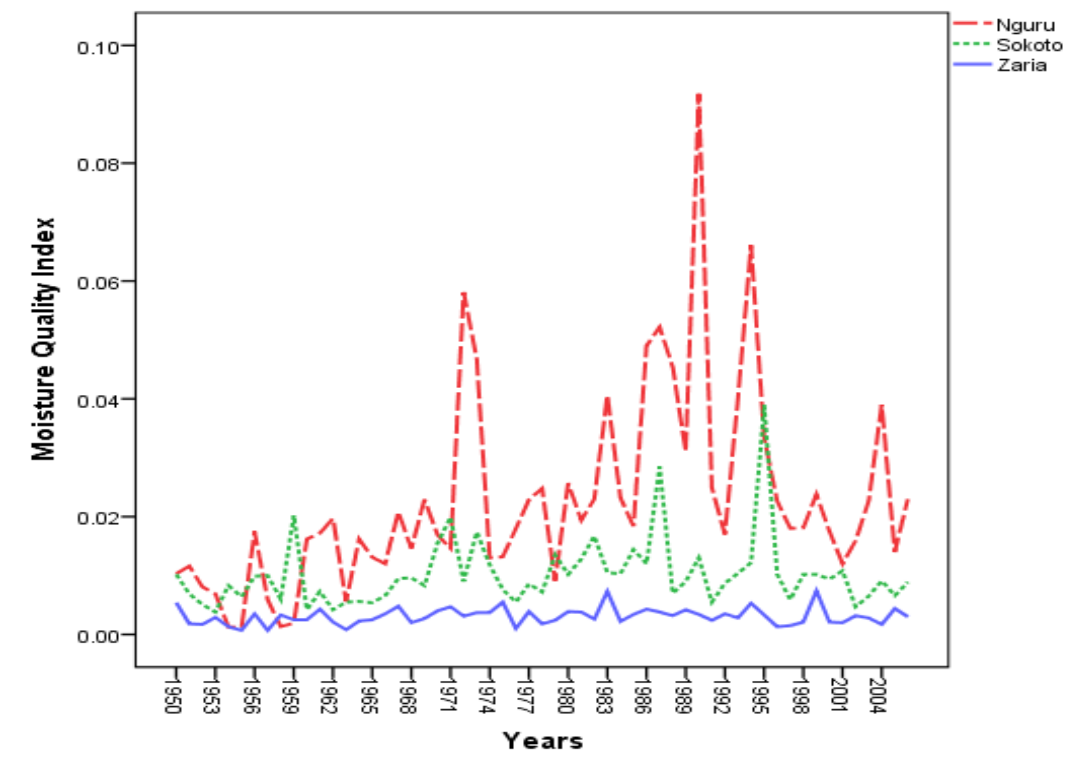

Fig. 2: MQI Variability 
Fundamentally, researches have shown that distribution of rainfall is crucial for agricultural productivity across the sub-humid and semi-arid zones of Nigeria. Effective rainfall onsets, length of the rainy season, peak and cessation of seasonal rains have very significant impact on agricultural intensification and these are threatened by increase variability. Usman (2000) affirmed the fact that variability in seasonal rainfall is the most import regulatory factor of agricultural activities. The effective onset of monsoon is very critical for agricultural productivity as it determine planting and germination of crops in rainfed agriculture. Thus, the IRMI developed was used to identify effective onset dates, potential onset related hazard and early warning scheme as a proactive approach towards disaster risk reduction (table.3). By implication if rainfall is not effective before $36^{\text {th }}$ Pentad ( $30^{\text {th }}$ June) is a signal of mild drought-fast maturing species should be planted (advisory) and effective onset beyond $43^{\text {rd }}$ pentad ( $5^{\text {th }}$ August) is an indication of very severe drought that necessitate the need for an emergency response as there may be no crop that grow to maturity before September cessation across the sub-humid and semi-arid zones of west Africa. Thus, this is crucial strategy for adaptation to late onset of rainfall as well will mitigate the effect on relevant socio-economic sector like agriculture.

Table2: Drought Early Warning Scheme Using Effective Onset Dates.

\begin{tabular}{|l|l|l|}
\hline $\begin{array}{l}\text { Effective Onset Dates (pentad } \\
\text { number) }\end{array}$ & $\begin{array}{l}\text { Onset phase Drought (moisture } \\
\text { deficit) Intensity }\end{array}$ & Early Warning Phase \\
\hline $30^{\text {th }}$ June $\left(36^{\text {th }}\right)$ & Mild & Advisory \\
$25^{\text {th }}$ July $\left(41^{\text {st }}\right)$ & Severe & Alert \\
$5^{\text {th }}$ August $\left(43^{\text {rd }}\right)$ & Very severe & Emergency \\
\hline
\end{tabular}

Source: Usman and Abdulkadir 2013

Similarly, seasonal potential hazard such as dry spell and drought during the growing season after effective onset of rains can be monitored at individual farm level using drop in IRMI values (Table 2). This is use to determine the significance of moisture stress and appropriate early warning; advisory, alert and emergency for varying level of moisture stress identified throughout the growing season. Most droughts across the agricultural intensive zones of sub-humid and semi-arid zones are mostly as result of moisture stress intensification after effective onset. Agricultural drought is the most common of all droughts type and is the most challenging to track and forecast owing to its ease of occurrence and impact on socio-economic sustainability (Usman and Abdulkadir 2013). Hence an agricultural early warning scheme developed for crop monitoring with a very high degree of drought forecast accuracy is fundamental for adequate drought preparedness and adaptation across the agricultural intensive area of sub-humid and semi- arid zones of West Africa.

TABLE 3: Drought Early Warning Using Drop in IRMI Values 


\begin{tabular}{|l|l|l|l|l|}
\hline DROP IN IRMI & INTERPRETATION & \multicolumn{2}{|l|}{ EARLY WARNING STATEMENT } \\
\cline { 3 - 5 } & & Advisory Phase & Alert Phase & Emergency Phase \\
\hline Drop $\leq 0.1$ & Not significant & $\begin{array}{l}\text { Two successive } \\
\text { Occurrences }\end{array}$ & $\begin{array}{l}\text { Three Successive } \\
\text { Occurrences }\end{array}$ & $\begin{array}{l}\text { Six Successive } \\
\text { Occurrences }\end{array}$ \\
\hline $0.1<$ Drop $<0.3$ & Significant & One Occurrence & $\begin{array}{l}\text { Two Successive } \\
\text { Occurrences }\end{array}$ & $\begin{array}{l}\text { Four Successive } \\
\text { Occurrences }\end{array}$ \\
\hline Drop $\geq 0.3$ & Highly significant & & One Occurrence & $\begin{array}{l}\text { Two Successive } \\
\text { Occurrences }\end{array}$ \\
\hline
\end{tabular}

Source: Usman and Abdulkadir 2013

In additional, the variability typical of the growing season is vital for identification of the species that are suitable for each location as an adaptation strategy to the recurring crop failure in the zone. The shortest growing seasons are along the semi-arid zone of north eastern Nigeria followed by Sokoto to extreme North West and Zaria which in sub-humid zone (Fig. 3). Since the index is capable of determining the moisture effectiveness throughout the growing season from onset to cessation. The information is essential for building the farmers capacity to adapt the right and most suitable crop specie for higher output in precarious moisture condition as tool for the management of seasonal related disaster.

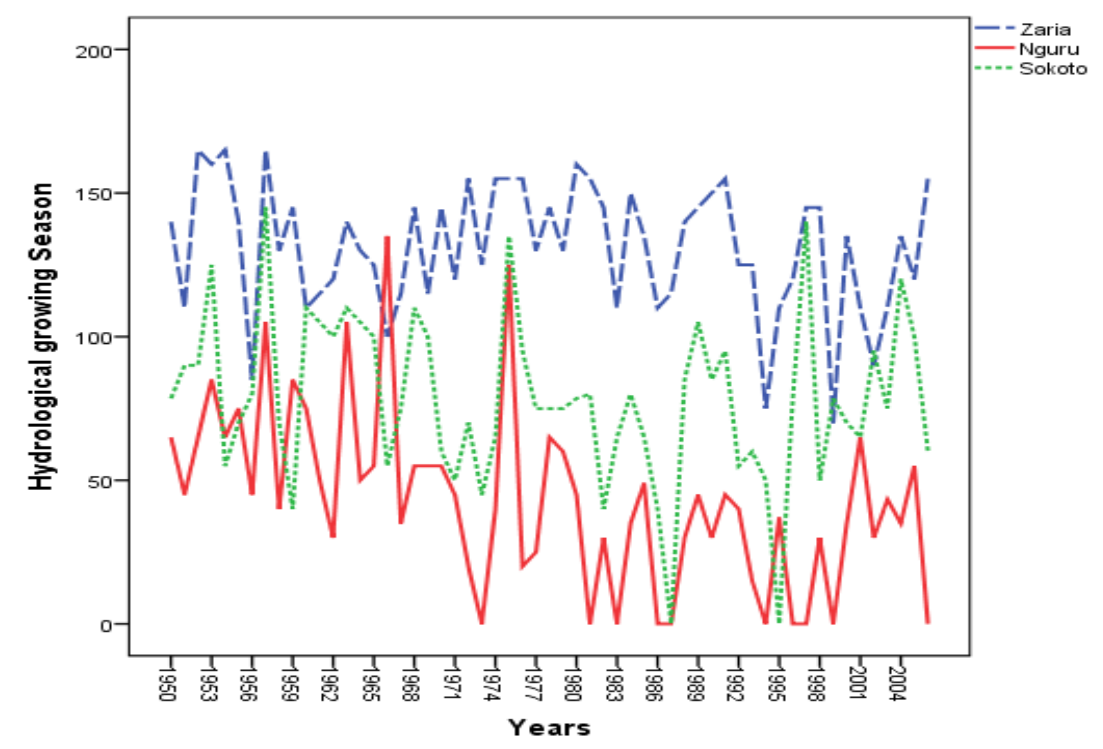

Fig. 2: Hydrological growing Season Variability

Similarly, the recurring flood that characterized the current decades affects large proportion of the country particularly the floodplain areas which are generally fertile but vulnerable to recurring flood which is disastrous to the agricultural sector. Flood usually occur in the low land areas when the flow of water in the river or stream channel is beyond the carrying capacity of the channel, the excess then overflows the banks to form flood water (particularly after discharge from dams). This is the most frequent and widespread environmental hazard in recent time across the country 
although the magnitude varies; the 2011, 2012, 2015, 2016 and 2017 flood events were disastrous. Discharge value above $1500 \mathrm{~m}^{3} \backslash \mathrm{sec}$ or above $1300 \mathrm{~m}^{3} \backslash \mathrm{sec}$ for more than a month during the hydrological growing season may be an indication of downstream flooding, as the run off may be too much that the river may over flow its banks (Abdulkadir 2010). Nigerian 2012 floods began in early July and pushed rivers over their banks, by November the floods had forced an approximately millions of people out from their homes, claimed hundreds of lives and hundreds of thousands of acres of farmland were submerged according to Nigeria's National Emergency Management Agency. The effects of flood on human livelihood necessitate the identification and development of early warning scheme as proactive adaptation strategies for sustainable agricultural intensification (table 2). A single weather event - be it a flood or a draught event - often translate to disproportionate loss of lives, household incomes, and property (Kevin, 2014). Hence, it's crucial to monitor the moisture quality, identify suitable crops (moisture loving crops) for most vulnerable areas to enhance sustainability of agricultural intensification, economic diversification human livelihood, food and regional security.

The effect of rainfall variability is not solely on agriculture and other relevant socio-economic activities but also on the natural environment and its vital resources (water, land and vegetation) that man rely on for survival. Existing literature indicates increasing trend toward of aridity in recent times (Hanafi and Jauffret, 2008; López et al., 2008; Gaughan and Waylen, 2012). It pertinent to note that investigations of the climatic characteristic across the sub-humid and semiarid zones of Nigeria have signals the fact that desert condition have grew significantly. Land degradation and aridity are fundamental challenge to agricultural productivity in West Africa and by implication diminishing pasture that is aggravating southward migration of human population and nomads. Sequentially, these have been a threat to sustainable livelihood in the fragile ecosystem. Eco-climatic factors moisture effectiveness is progressively declining (Late rainfallrelated onset, early cessation, shorter HGS, decreasing AI values and deficient MQI) signifying aridity in the zone (Abdulkadir et.al 2013a). The decline trend in moisture effectiveness have continued to intensified moisture stress across the sub-humid and semi-arid zone in the last six decades signifying the fact that decrease moisture effectiveness is a prime aridity factor in the subregion. Identification of this is crucial to development of adaptation strategies as pathway towards the attainment of sustainable agricultural intensification and human livelihood across this fragile ecosystem.

The dynamics in the eco-climatic moisture effectiveness across the zone necessitate the identification of the current state of the environment. The risks associated with these changes are real but highly uncertain (Ann et al., 2013). Thus, Abdulkadir et.al (2015) integrated MQI, onset and cessation dates, HGS, Aridity Index period (1950-2006) and vegetation index theoretically base on the fact that aridity index, cessation dates, length of the hydrologic growing season and vegetation index are directly proportional to eco-climatic zone changes while those for onset and MQI are inversely proportional. With the temperature increasing and precipitation fluctuations, water availability and crop production are likely to decrease in the future (Yinhong et.al 2009).

This indicate the need for using effective operational index for up-dating the classical eco-climatic and agro-climatic maps that dominate decision making across West Africa for the development of appropriate adaptation strategy. This identified five eco-climatic classes; semi-arid/ arid, dry sub-humid, sub-humid, humid and wet eco-climatic zones as against the broad classic climatic 
zones; tropical continental north, tropical hinterland. The derived map clearly visualized the vulnerability of the sub-humid and semi-arid zones to drought, aridity and crop failure.

This is sensitive to climatic variation across fragile ecosystem and fundamental tool for adaptation to the climate variability and change, sustainability agricultural intensification, poverty alleviation and enhance human livelihood. Africa's responses to climate change require fundamental rethinking (Kevin, 2014). Thus, there is need to identify and address the core issue militating against the African agricultural intensification, economic diversification, poverty eradication, food and regional security programmes. It is important to find out what has not worked previously and why, before taking any steps to develop the agriculture or the economy (Omorogbe et. al, 2014). The impact of these changes made it paramount to identify better and realistic strategies for adaptation and mitigation to ever changing state of the environment through improve and operational climate prediction for enhanced rainfall monitoring as pathway towards the attainment of sustainable crop production/agricultural intensification and enhance livelihood across these fragile ecosystem.

\section{Conclusion}

Generally, erratic moisture conditions; breaks, dry spells, drought and land degradation, are fundamental challenges to agricultural productivity in West Africa. In addition, aggravating crop failure and diminishing pasture have continued to serve as push factors for the southward migration of human populations and nomadic pastoralists. Consequently, there is an urgent need to incorporate fundamental adaptation strategies into regional and national development plans for enhanced agricultural resilience and sustainable livelihoods in these fragile ecosystems. Diverse but complementary information on the state of the environment were identified for better and realistic development of adaptation strategies to ever changing state of the environment. This was based on improve and operational climate prediction to enhanced rainfall monitoring as pathway towards the attainment of sustainable crop production/agricultural intensification and enhance livelihood across these fragile ecosystem. Integration of effective and efficient seasonal forecast, early warning scheme, identification, understanding and adapting to spatiotemporal changes are cost-effective eco-friendly strategies to minimize extreme climatic conditions, environmental degradation, promote sustainable livelihoods, and encourage sound national and regional economic diversification programmes. The degree of environmental degradation and erratic moisture that characterizes the entire semi-arid and dry sub-humid zones across West Africa necessitates adoption of climatic uncertainty information as prime input into the planning and implementation of national and regional agricultural intensification, economic diversification and poverty eradication pragrammes.

\section{References}


Abdulkadir A. (2010): Flood Vulnerability Assessment for Enhanced Utilization of Wetland Ecosystem Downstream of Jebba Hydroelectric Dam. Journal of Flood Engineering (JFE) volume 2, number 1-2 Pp 37-48.

AbdulKadir, A., Usman, M. T. and Shaba, A. H. (2015) An integrated approach to delineation of the eco- climatic zones in Northern Nigeria. Journal of Ecology and the Natural Environment. Vol. 7(9), pp. 247-255

AbdulKadir, A., Usman, M.T. and Shaba, A.H. (2013), "Climate change, aridity trend and agricultural sustainability of the Sudano-Sahelian belt of Nigeria", International Journal of Development and Sustainability, Vol. 2 No. 2, pp. 1436-1456.

Anselm A. E, and Taofeeq A. A. (2010) Challenges of Agricultural Adaptation to Climate Change in Nigeria: a Synthesis from the Literature. Field Actions Science Reports. Vol. 4 (2010) Pp 1-11

Beno^1t S. (2012) Present and future climate change in the semi-arid region of West Africa: a crucial input for practical adaptation in agriculture. Atmos. Sci. Let. (2012). (wileyonlinelibrary.com) DOI: 10.1002/asl.368

Bruce M. C., Philip T., Robert Z., Piet-van A. and Leslie L. (2014) Sustainable intensification: What is its role in climate smart agriculture? Current Opinion in Environmental Sustainability 8: $39-43$

Emmanuel M. A. and Fanan U. (2013) Effect of Variability in Rainfall Characteristics on Maize Yield in Gboko, Nigeria. Journal of Environmental Protection, 2013, 4, 881-887.

FAO (2002) The state of food insecurity in the world 2001. Food and Agriculture Organization, Rome.

FAO (2010) Water and Cereals in Drylands. Rome Published by The Food and Agriculture Organization of the United Nations and Earthscan web

FAO (2013) Resilient Livelihoods - Disaster Risk Reduction for Food and Nutrition Security Framework Programme.

Food and Agriculture Organization (2008), "Climate Change and Food Security: a framework document".

Gaoussou T. and Erika S. (2015) Improving and Scaling Up SRI in West Africa: Insights from a regional, 13-country project .Centre National de Spécialisation sur le Riz, IER Mali, and SRI-Rice, Cornell University A Success Story https://www.slideshare.net/SRI. CORNELL/1507-improvingand-scaling-up-sri-in-west-africa-a-success-story

Gaughan, A.E. and Waylen, P.R. (2012), "Spatial and temporal precipitation variability in the Okavango-Kwando-Zambezi catchment, southern Africa", Journal of Arid environments, Vol. 82, pp. 19-30. 
GHI (2012) The Challenge of Hunger: Ensuring Sustainable Food Security Under Land, Water and Energy Stress. http://ebrary.ifpri.org/cdm/ref/collection/p15738coll2/id/127150

Giovannucci D., Scherr S., Nierenberg D., Hebebrand D., Shapiro J., Milder J., and Wheeler K. (2012). Food and Agriculture: the future of sustainability. A strategic input to the Sustainable Development in the 21st Century (SD21) project. New York: United Nations Department of Economic and Social Affairs, Division for Sustainable Development.

Gukurume S. (2013), Climate Change, Variability and Sustainable Agriculture in Zimbabwe's Rural Communities. Russian Journal of Agricultural and Socio-Economic Sciences, 2(14), Pp. 89 -100 .

Hanafi, A. and Jauffret, S.A. (2008), "Long-term vegetation dynamics useful in monitoring and assessing desertification processes in the arid steppe, southern Tunisia", Journal of Arid Environments, vol. 72 No. 4, pp. 557-572.

Hansen, J., R. Ruedy, M. Sato, and K. Lo (2010), Global surface temperature change. Reviews of Geophysics, Vol. 48, 1-27

Jamal S. (2015) Confronting Drought in Africa's Drylands; Opportunities for Enhancing Resilience. The Sahel \& West Africa Week, EXPO 2015 Milan, Italy; 26-30 October

Kevin C. U. (2014), Solving Africa's Energy Challenges by 2025. A Paper Presented at the Africa Progress Panel (APP) in preparation for the 2015 edition of the Africa Progress Report held at Geneva, 30 October 2014

López B, C., Holmgren M., Sabate' A. and C.A. Gracia (2008) Estimating Annual Rainfall Threshold for Establishment of Tree Species in Water-limited Ecosystems Using Tree-ring Data. Journal of Arid Environments, Volume 72, Issue 5, Pp 602-611

Mary N. E. and Chukwudi N. E. (2014) Irrigation Schedules for Selected Food Crops Using Water Balance Book-Keeping Method. AGRICULTURA TROPICA ET SUBTROPICA, 47/3, 87-93, 2014

Mary, A.L. and Majule, A.E. (2009) Impacts of Climate Change, Variability and Adaptation Strategies on Agriculture in Semi Arid Areas of Tanzania: The Case of Manyoni District in Singida Region, Tanzania. African Journal of Environmental Science and Technology, 3, 206-208

Masihi I., Maskey s., Mussá F.E.F. and Trambauer P. ( 2014)A review of droughts on the African continent: a geospatial and long-term perspective. Hydrol. Earth Syst. Sci., 18, 3635-3649.

Menghestab H.(2005) Weather patterns, food security and humanitarian response in sub-Saharan Africa. Phil. Trans. R. Soc. B (2005) 360, 2169-2182

Omorogbe O., Zivkovic J. and Ademoh F. (2014) The Role of Agriculture in the Economic Development of Nigeria. European Scientific Journal vol.10, No.4 ISSN: 1857 - 7881 
Propastin, P.; Fotso, L.; Kappas, M. (2010) Assessment of vegetation vulnerability to ENSO warm events over Africa. Int. J. Appl. Earth Obs. Geoinf. 2010, 12S, S83-S89.

Richard R. H. (2015) An overview of weather and climate extremes -Products and trends. Weather and Climate Extremes. Vol 10, pp. 1-9

Shabbir A.S. and Abdullah A. (2013) Sustainable Food Production in marginallands; Case of GDLA Member Countries. International Soil Conservation Resarch, Vol. 1, Pp. 24-38

Sharon E. Nicholson (2013) The West African Sahel: A Review of Recent Studies on the Rainfall Regime and Its Interannual Variability. ISRN Meteorology, Volume 2013, Article ID 453521, 32 pages

Taalas P. (2016), Global climate breaks new records January to June 2016. WMO Report Geneva, 21 July 2016. http://public.wmo.int/en/media/press-release/global-climate-breaks-new-recordsjanuary-june-2016 (Access 13 march, 2017)

Temesgen D. Yahualashet H. and Ragan D.S. (2014) Climate Change Adaptations of Smallholders Farmers in South Eastern Ethiopia. Journal of Agricultural Extension and Rural Development, Vol. 6 (11). Pp 354-366

Usman M.T. and Abdulkadir A. (2012) On Determining the 'Real' Onset Date of Seasonal Rains in the Semi-Arid and Sub-Humid Areas of West Africa. Natural Hazard (NHAZ). Volume 66, Issue 2, pp 749-758.

Usman MT, Archer ERM, Johnston P, Tadross M (2005) A conceptual framework for enhancing the utility of rainfall hazard forecasts for agriculture in marginal environments. Nat Hazards $34: 111-129$

Usman MT. (2000) An operational index for assessing inter annual rainfall variability and agricultural droughts over the Sahel. Afr. Climatol. Res. Ser. 3(1): 23-33.

Usman, M. T. and AbdulKadir, A. (2014) An Experiment in Intra- seasonal Agricultural Drought Monitoring and Early Warning in the Sudano-Sahelian Belt of Nigeria. International Journal of Climatology, Volume 34, Issue 7, pages 2129-2135.

Winkler K., Gessner U. and Hochschild V. (2017) Identifying Droughts Affecting Agriculture in Africa Based on Remote Sensing Time Series between 2000-2016: Rainfall Anomalies and Vegetation Condition in the Context of ENSO. Remote Sens., 9, 831 Pp. 1-27

Wheeler, T. and von Braun, J. (2013) Climate Change Impacts on Global Food Security. Science, 341, 508-513. http://dx.doi.org/10.1126/science.1239402 (Accessed 27th November 2017)

Yinhong K., Shahbaz K. and Xiaoyi M. (2009)Climate change impacts on crop yield, crop water productivity and food security - A review Progress in Natural Science 19, 1665-1674. 